\title{
An Analytical Method for Evaluating the Dynamic Response of Plates Subjected to Underwater Shock Employing Mindlin Plate Theory and Laplace Transforms
}

\author{
Zhenyu Wang, Xu Liang, and Guohua Liu \\ College of Civil Engineering and Architecture, Zhejiang University, Hangzhou 310058, China \\ Correspondence should be addressed to Xu Liang; liangxu@zju.edu.cn
}

Received 2 March 2013; Accepted 25 April 2013

Academic Editor: Zhuming Bi

Copyright (c) 2013 Zhenyu Wang et al. This is an open access article distributed under the Creative Commons Attribution License, which permits unrestricted use, distribution, and reproduction in any medium, provided the original work is properly cited.

It is often in the interest of a designer to know the transient state of stress in a plate subjected to an underwater explosion. In this paper, an analytical method based on Taylor's fluid-solid interaction (FSI) model, Mindlin plate theory, Laplace transform, and its inversion is proposed to examine the elastic dynamic response of a plate subjected to an underwater explosion. This analytical method includes shear deformation, the moments and membrane stress in the plate, and the FSI effect and considers a full profile of possibilities. The results of the response-time histories and the response distribution on the plate in terms of displacements and stresses from the analytical method are compared with finite element analysis (FEA) to validate this method, and the comparison indicates good agreement. Comparison of the acceleration at the center of an air-backed plate between the analytical method and the experiment from relevant literature, shows good agreements, and the analytical method and its FSI model are validated. The influence of the FSI is investigated in detail. All extreme values of the response-time histories decrease as the thickness increases for the non-FSI case. The results can be used as benchmark solutions in further research.

\section{Introduction}

Plate element is one of the basic elements of every class of ship and apparatus and may be subjected to underwater explosions. It is in the interest of a ship designer to know the transient state of stress in advance that develops in a plate during an underwater explosion. For low-intensity explosions, the stresses developed within a plate are usually within the material's elastic range [1-3].

The classical plate theory (CPT) has been used to solve the response in thin plates to an underwater explosion. An orthotropic and simply supported plate reinforced by stiff particles embedded in a matrix offers the potential for simple, economically functional grading and enhanced response. Genin and Birman [4] obtained a solution for the response of this plate under a uniform and time-varying overpressure using the Kirchhoff plate theory and a convolution integral. However, the shear deformation through the thickness is neglected within CPT, and the effect of fluid-solid interaction (FSI) was not considered in this research.
Some of recent research on this subject have been devoted to the extension of linear to nonlinear response by involving von Kármán thin plate theory and employing the extended Galerkin and the Runge-Kutta methods. Hause [5] investigated the nonlinear response of a functionally graded plate with two constituent phases exposed to a Friedlander explosive air blast within the classical plate theory, but the effect of fluid-solid interaction (FSI) was not considered in this research. Librescu et al. [6-9] have developed a three-dimensional sandwich model which is used in the investigation of the dynamic responses of a sandwich plate subjected to underwater explosions by employing Hayman's FSI model $[6,7]$. In the sandwich model, core layer can only carry transverse shear stresses, while the transverse shear effects are neglected for the face sheets. In general, all of above research concerning the nonlinear response are numerical but not analytical.

The phenomenon of FSI significantly influences the dynamic response of a structure during an underwater explosion. The influence of FSI is typically investigated by finite 
element analysis (FEA) which provides a detailed picture depending on the level of complexity of the model [10-13]. The discretization used both for spatial derivation and time integration, however, affects spurious oscillations and the accuracy of a numerical solution [14].

Taylor [15] proposed a one-dimensional FSI model for a planar shock wave impinging on a freestanding plate and considered the momentum transmitted to the plate by the shock wave. Liu and Young [16] extended Taylor's air-backed FSI model to a water-backed FSI model and systematically investigated the influence of the back conditions on the interaction between the fluid and the structure. Utilizing Taylor's FSI model, the energy method, and considering the conditions of the air-backed and water-backed cases, Rajendran et al. [1-3] derived one-dimensional, semianalytical models to predict the elastic strains in circular and rectangular plates subjected to underwater explosions. Good agreement was found between the model and the experimental results. However, these solutions considering the FSI effect are one-dimensional and ignore moment and membrane stress in the plate. In addition to elastic method, plastic dynamic analytical solutions for the response of a three-layered sandwich plate with a soft core to UNDEX have also formed the subject of recent studies [11, 17-20], in which the existing plastic solution procedure generally comprises three stages. However, the velocity is assumed to be uniform for the front and back faces of the sandwich plate except for the boundaries in the FSI phase, with the FSI differences between the different positions on front and back faces of plate being ignored, that is to say, only one-dimensional FSI effect is considered.

A comprehensive review on the methods for the response of plates to underwater explosion is present above. It is worthy noted that the analytical methods mentioned above do not consider the FSI differences between the different positions on front and back faces of plate. The purpose of this paper is to fill this gap by proposing an analytical method to determine the elastic dynamic response of a plate subjected to an underwater explosion based on Taylor's FSI model, Mindlin plate theory, Laplace transform, and its inversion. This method considers the full profile of possibilities, such as non-FSI, air-backed, and water-backed cases. Section 1 introduces the solution methods. In Section 2, the problem is described and Taylor's FSI model, the air-backed, and the water-backed cases are introduced. Section 3 introduces the governing equations of motion for Mindlin plate theory. In Section 4, analytical solutions for the three cases are derived by Fourier transform, Laplace transform, and their inversion. In Section 5, the analytical results are validated by being compared with those from the FEA and the experiment record, and the influences of the FSI and material thickness are investigated. The conclusions are discussed in Section 6.

\section{Problem Description and Fluid-Solid Interaction}

Consider a rectangular plate of length $a$, width $b$, and a uniform thickness $h$, as shown in Figure 1. The plate is

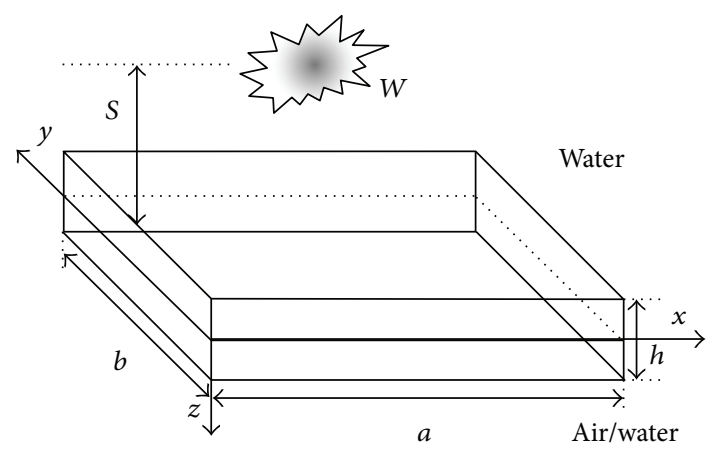

FIGURE 1: A rectangular plate subjected to an underwater explosion showing dimensions and the Cartesian coordinate system.

subjected to an underwater explosion from an explosive charge $W$ (TNT equivalent weight in $\mathrm{kg}$ ) located at a distance $S$ (in $m$ ) from the center of the plate.

Taylor [15] proposed a one-dimensional FSI model for a planar shock wave impinging on a free-standing plate, including the momentum transmitted to the plate by the shock wave. This FSI model has been widely used in analytical methods modeling the plastic response of plates subjected to an underwater explosion $[17,19,20]$ and is briefly reviewed below.

Adopting the planar wave assumption, the water pressure $p_{f}(x, y, t)$ at the front face $(z=-h / 2)$ comprises the incident wave $p_{i}(x, y, t)$, the idealized perfectly reflected wave $p_{r 1}(x, y, t)$, and the rarefaction wave pressure $p_{r 2}(x, y, t)$, respectively, as follows [15]:

$$
\begin{aligned}
p_{f}(x, y, t) & =p_{i}(x, y, t)+p_{r 1}(x, y, t)+p_{r 2}(x, y, t) \\
& =2 p_{m} \exp \left(-\frac{t}{t_{d}}\right)-\rho_{w} c_{w} \dot{w}\left(x, y, z=-\frac{h}{2}, t\right),
\end{aligned}
$$

where $w$ denotes the deflection of the plate and the dots over a quantity stand for time derivatives.

The peak pressure $p_{m}$ and the time parameter $t_{d}$ of the incident wave are given as follows $[1,21]$ :

$$
\begin{gathered}
p_{m}=52.16 \times\left(\frac{W^{1 / 3}}{S}\right)^{1.13} \mathrm{MPa} \\
t_{d}=96.5 \times 10^{-3} \times W^{1 / 3} \times\left(\frac{W^{1 / 3}}{S}\right)^{-0.22} \mathrm{msec} .
\end{gathered}
$$

Two backing condition categories are water-backed and air-backed. For an air-backed plate, the water pressure at the back face $(z=h / 2)$ is [1]

$$
p_{b}(x, y, t)=0,
$$

and for a water-backed plate, the pressure at the back face is [1]

$$
p_{b}(x, y, t)=-\rho_{w} c_{w} \dot{w}\left(x, y, z=\frac{h}{2}, t\right) .
$$


To compare the two cases with the FSI effects between the plate and the water, a non-FSI case (ignoring FSI effects) is also discussed. The water pressures at both front and back faces can be expressed as follows [1]:

$$
\begin{gathered}
p_{f}(x, y, t)=p_{m} \exp \left(-\frac{t}{t_{d}}\right), \\
p_{b}(x, y, t)=0 .
\end{gathered}
$$

\section{Fundamental Equations}

Considering an orthotropic material, the Mindlin plate theory implies that the displacements are distributed in the plate as follows:

$$
\begin{aligned}
& u=-z \psi_{x z}, \\
& v=-z \psi_{y z}, \\
& w=w_{0},
\end{aligned}
$$

where $w_{0}$ is the vertical displacement at the middle surface.

The moment and shear force resultants can be written in terms of the displacements as

$$
\begin{gathered}
{\left[\begin{array}{l}
M_{x} \\
M_{y} \\
M_{x y}
\end{array}\right]=\frac{h^{3}}{12}\left[\begin{array}{ccc}
c_{11} & c_{12} & 0 \\
c_{12} & c_{22} & 0 \\
0 & 0 & c_{66}
\end{array}\right]\left[\begin{array}{c}
-\psi_{x z, x} \\
-\psi_{y z, y} \\
-\left(\psi_{x z, y}+\psi_{y z, x}\right) \\
2
\end{array}\right],} \\
{\left[\begin{array}{l}
Q_{y} \\
Q_{x}
\end{array}\right]=\frac{\kappa h}{2}\left[\begin{array}{cc}
c_{44} & 0 \\
0 & c_{55}
\end{array}\right]\left[\begin{array}{l}
w_{0, y}-\psi_{y z} \\
w_{0, x}-\psi_{x z}
\end{array}\right],}
\end{gathered}
$$

where $\psi_{x z}$ and $\psi_{y z}$ are the rotations about the $x$ - and $y$-axes, respectively, $h$ is the thickness of the plate, $\kappa$ is the shear correction factor (taken as 5/6), and $c_{11}, c_{12}, c_{22}, c_{44}, c_{55}$, and $c_{66}$ are the elastic constants. Throughout the paper, a comma after a quantity denotes a particular differentiation with respect to the spatial coordinates.

The normal stresses are distributed as

$$
\begin{aligned}
& \sigma_{x x}=\frac{12 z M_{x}}{h^{3}}, \\
& \sigma_{y y}=\frac{12 z M_{y}}{h^{3}}, \\
& \sigma_{z z}=0,
\end{aligned}
$$

and the shear stresses are distributed as

$$
\begin{aligned}
\sigma_{x y} & =\frac{12 z M_{x y}}{h^{3}}, \\
\sigma_{x z} & =\frac{3\left(1-4 z^{2} / h^{2}\right) Q_{x}}{(2 h)}, \\
\sigma_{y z} & =\frac{3\left(1-4 z^{2} / h^{2}\right) Q_{y}}{(2 h)} .
\end{aligned}
$$

The von Mises stress $\sigma_{m}$ can be expressed as

$$
\sigma_{m}=\sqrt{\frac{\left[\left(\sigma_{x x}-\sigma_{y y}\right)^{2}+\left(\sigma_{x x}-\sigma_{z z}\right)^{2}+\left(\sigma_{y y}-\sigma_{z z}\right)^{2}+6\left(\sigma_{x y}^{2}+\sigma_{x z}^{2}+\sigma_{y z}^{2}\right)\right]}{2} .}
$$

The governing equations of motion for the Mindlin plate theory are

$$
\begin{gathered}
M_{x, x}+M_{x y, y}+\rho_{p} J \ddot{\psi}_{x z}=Q_{x}, \\
M_{x y, x}+M_{y, y}+\rho_{p} J \ddot{\psi}_{y z}=Q_{y}, \\
Q_{x, x}+Q_{y, y}-\rho_{p} h \ddot{w}_{0}+p_{f}+p_{b} .=0,
\end{gathered}
$$

where $J=h^{3} / 12$

Substituting (7) into (11) allows (11) to be rewritten as

$$
\begin{aligned}
& \frac{h^{3}\left[2\left(c_{11} \psi_{x z, x x}+c_{12} \psi_{y z, x y}\right)+c_{66}\left(\psi_{x z, y y}+\psi_{y z, x y}\right)\right]}{24} \\
& -\frac{h^{3} \rho_{p} \ddot{\psi}_{x z}}{12}+\frac{c_{55} \kappa h\left(w_{0, x}-\psi_{x z}\right)}{2}=0, \\
& \frac{h^{3}\left[2\left(c_{12} \psi_{x z, x y}+c_{22} \psi_{y z, y y}\right)+c_{66}\left(\psi_{x z, x y}+\psi_{y z, x x}\right)\right]}{24} \\
& -\frac{h^{3} \rho_{p} \ddot{\psi}_{y z}}{12}+\frac{c_{44} \kappa h\left(w_{0, y}-\psi_{y z}\right)}{2}=0, \\
& \frac{\rho_{p} h \ddot{w}_{0}-\kappa h\left[c_{55}\left(w_{0, x x}-\psi_{x z, x}\right)+c_{44}\left(w_{0, y y}-\psi_{y z, y}\right)\right]}{2} \\
& =p_{f}+p_{b} .
\end{aligned}
$$

Assuming the plate is simply supported, the edge conditions are given as

$$
\begin{aligned}
& x=0, \quad a: w_{0}=\psi_{y z}=M_{x}=0, \\
& y=0, \quad b: w_{0}=\psi_{x z}=M_{y}=0 .
\end{aligned}
$$

The following Fourier series expansions for the displacements satisfy (15):

$$
\begin{gathered}
w_{0}=\sum_{m=1}^{\infty} \sum_{n=1}^{\infty} \bar{w}_{0} \sin \alpha_{m} x \sin \beta_{n} y, \\
\psi_{x z}=\sum_{m=1}^{\infty} \sum_{n=1}^{\infty} \bar{\psi}_{x z} \cos \alpha_{m} x \sin \beta_{n} y, \\
\psi_{y z}=\sum_{m=1}^{\infty} \sum_{n=1}^{\infty} \bar{\psi}_{y z} \sin \alpha_{m} x \cos \beta_{n} y,
\end{gathered}
$$

where

$$
\alpha_{m}=\frac{m \pi}{a}, \quad \beta_{n}=\frac{n \pi}{a},
$$

and $m, n=1,2 \ldots$ are the number of half waves in the $x$ and $y$ directions, respectively, and the overscript $\left(^{-}\right)$denotes the transformed function in the Fourier domain. 
According to the plane wave assumption, the incident wave and the idealized perfectly reflected wave can also be expanded in Fourier series form as

$$
\begin{gathered}
p_{i}=\sum_{m=1}^{\infty} \sum_{n=1}^{\infty} \bar{p}_{i} \sin \alpha_{m} x \sin \beta_{n} y \\
\bar{p}_{i}=\frac{4}{a b} \int_{0}^{a} \int_{0}^{b} p_{i} \sin \alpha_{m} x \sin \beta_{n} y d x d y=\frac{4 \eta_{1} p_{i}}{a b} \\
p_{r 1}=\sum_{m=1}^{\infty} \sum_{n=1}^{\infty} \bar{p}_{r 1} \sin \alpha_{m} x \sin \beta_{n} y \\
\bar{p}_{r 1}=\frac{4}{a b} \int_{0}^{a} \int_{0}^{b} p_{r 1} \sin \alpha_{m} x \sin \beta_{n} y d x d y=\frac{4 \eta_{1} p_{r 1}}{a b},
\end{gathered}
$$

where

$$
\eta_{1}=\frac{\left[-1+(-1)^{m}\right]\left[-1+(-1)^{n}\right]}{\left(m n \pi^{2}\right)} .
$$

\section{Solutions Procedure}

The analytical solutions in the Fourier and Laplace transformed domains are derived for the three cases, respectively. The final solutions to the displacement distributions are obtained by the inversion of the Fourier and Laplace transforms. The inversion of Laplace transform is carried out analytically.

4.1. Non-FSI. For the non-FSI case, by substituting (5) and (16)-(19) into (12)-(14), the fundamental equation can be rewritten in the Fourier transformed domain as follows:

$$
\begin{array}{r}
\frac{h^{3} \rho_{p} \ddot{\bar{\psi}}_{x z}}{12}+\bar{\psi}_{x z}\left[\frac{h^{3}\left(2 c_{11} \alpha_{m}^{2}+c_{66} \beta_{n}^{2}\right)}{24}+\frac{c_{55} h \kappa}{2}\right] \\
+\frac{\left(2 c_{12}+c_{66}\right) h^{3} \alpha_{m} \beta_{n} \bar{\psi}_{y z}}{24}-\frac{c_{55} h \kappa \bar{w}_{0} \alpha_{m}}{2}=0, \\
\frac{h^{3} \rho_{p} \ddot{\bar{\psi}}_{y z}}{12}+\bar{\psi}_{y z}\left[\frac{h^{3}\left(c_{66} \alpha_{m}^{2}+2 c_{22} \beta_{n}^{2}\right)}{24}+\frac{c_{44} h \kappa}{2}\right] \\
+\frac{\left(2 c_{12}+c_{66}\right) h^{3} \alpha_{m} \beta_{n} \bar{\psi}_{x z}}{24}-\frac{c_{44} h \kappa \bar{w}_{0} \beta_{n}}{2}=0, \\
h \rho_{p} \ddot{\bar{w}}_{0}+\frac{h \kappa \bar{w}_{0}\left(c_{55} \alpha_{m}^{2}+c_{44} \beta_{n}^{2}\right)}{2}-\frac{c_{55} h \kappa \alpha_{m} \bar{\psi}_{x z}}{2} \\
-\frac{c_{44} h \kappa \beta_{n} \bar{\psi}_{y z}}{2}=\frac{4 \eta_{1} p_{m} \exp \left(-t / t_{d}\right)}{a b} .
\end{array}
$$

The Laplace transform of the function $f(t)$ is defined as

$$
L[f(t)]=\tilde{f}(s)=\int_{0}^{\infty} f(t) e^{-s t} d t,
$$

where $s$ is the parameter of the Laplace transform and the overscript $(\sim)$ denotes the transformed function in the
Laplace domain. Applying the Laplace transform to (23)-(25) yields:

$$
\begin{aligned}
& {\left[\frac{h^{3}\left(2 c_{11} \alpha_{m}^{2}+c_{66} \beta_{n}^{2}+2 s^{2} \rho_{p}\right)}{24}+\frac{c_{55} h \kappa}{2}\right] \tilde{\bar{\psi}}_{x z}} \\
& +\frac{h^{3} \alpha_{m} \beta_{n}\left(2 c_{12}+c_{66}\right) \tilde{\bar{\psi}}_{y z}}{24}-\frac{c_{55} h \kappa \alpha_{m} \widetilde{\bar{w}}_{0}}{2}=0 \\
& {\left[\frac{h^{3}\left(c_{66} \alpha_{m}^{2}+2 c_{22} \beta_{n}^{2}+2 s^{2} \rho_{p}\right)}{24}+\frac{c_{44} h \kappa}{2}\right] \tilde{\bar{\psi}}_{y z}} \\
& +\frac{h^{3} \alpha_{m} \beta_{n}\left(2 c_{12}+c_{66}\right) \tilde{\bar{\psi}}_{x z}}{24}-\frac{c_{44} h \kappa \beta_{n} \widetilde{\bar{w}}_{0}}{2}=0 \\
& \frac{h \widetilde{\bar{w}}_{0}\left(c_{55} \kappa \alpha_{m}^{2}+c_{44} \kappa \beta_{n}^{2}+2 s^{2} \rho_{p}\right)}{2}-\frac{c_{55} h \kappa \alpha_{m} \tilde{\bar{\psi}}_{x z}}{2} \\
& -\frac{c_{44} h \kappa \beta_{n} \tilde{\bar{\psi}}_{y z}}{2}=\frac{4 \eta_{1} t_{d} p_{m}}{\left[a b\left(1+s t_{d}\right)\right]} .
\end{aligned}
$$

Solutions in the Fourier and Laplace transformed domains for the non-FSI case can be derived from (27)-(29) as follows:

$$
\begin{aligned}
& \widetilde{\bar{w}}_{0}=\frac{16 p_{m} t_{d} \eta_{1}\left(\eta_{3}^{2}-\eta_{2} \eta_{4}\right)}{\left[a b\left(1+s t_{d}\right) \eta_{6}\right]}, \\
& \widetilde{\bar{\psi}}_{x z}=\frac{8 h \kappa p_{m} t_{d} \eta_{1}\left(c_{44} \beta_{n} \eta_{3}-c_{55} \alpha_{m} \eta_{4}\right)}{\left[a b\left(1+s t_{d}\right) \eta_{6}\right]}, \\
& \tilde{\bar{\psi}}_{y z}=\frac{8 h \kappa p_{m} t_{d} \eta_{1}\left(c_{55} \alpha_{m} \eta_{3}-c_{44} \beta_{n} \eta_{2}\right)}{\left[a b\left(1+s t_{d}\right) \eta_{6}\right]},
\end{aligned}
$$

where

$$
\begin{aligned}
\eta_{2}= & \frac{h \kappa c_{55}}{2}+\frac{h^{3}\left(2 c_{11} \alpha_{m}^{2}+c_{66} \beta_{n}^{2}+2 s^{2} \rho_{p}\right)}{24}, \\
\eta_{3}= & \frac{h^{3}\left(2 c_{12}+c_{66}\right) \alpha_{m} \beta_{n}}{24}, \\
\eta_{4}= & \frac{h \kappa c_{44}}{2}+\frac{h^{3}\left(c_{66} \alpha_{m}^{2}+2 c_{22} \beta_{n}^{2}+2 s^{2} \rho_{p}\right)}{24}, \\
\eta_{5}= & \frac{h\left(\kappa c_{55} \alpha_{m}^{2}+\kappa c_{44} \beta_{n}^{2}+2 s^{2} \rho_{p}\right)}{2}, \\
\eta_{6}= & h^{2} \kappa^{2}\left[c_{44} \beta_{n}\left(c_{44} \beta_{n} \eta_{2}-2 c_{55} \alpha_{m} \eta_{3}\right)+c_{55}^{2} \alpha_{m}^{2} \eta_{4}\right] \\
& +4\left(\eta_{3}^{2}-\eta_{2} \eta_{4}\right) \eta_{5} .
\end{aligned}
$$

4.2. Air-Backed. Considering the FSI effects for an airbacked plate case and substituting (1), (3), and (16)-(19) into (12)-(14), the fundamental (12)-(13) that are rewritten in the Fourier transformed domain are the same as (23)-(24). These rewritten equations in both the Fourier and Laplace 
transformed domains are the same as (27)-(28), respectively. Moreover, (14) can be rewritten as follows:

$$
\begin{gathered}
\frac{c_{w} \rho_{w} \dot{\bar{w}}_{0}+h \rho_{p} \ddot{\bar{w}}_{0}-c_{55} h \kappa \alpha_{m} \bar{\psi}_{x z}}{2}-\frac{c_{44} h \kappa \beta_{n} \bar{\psi}_{y z}}{2} \\
+\frac{h \kappa \bar{w}_{0}\left(c_{55} \alpha_{m}^{2}+c_{44} \beta_{n}^{2}\right)}{2}=\frac{8 \eta_{1} p_{m} \exp \left(-t / t_{d}\right)}{a b} .
\end{gathered}
$$

Applying the Laplace transform to (32) yields:

$$
\begin{gathered}
\widetilde{\bar{w}}_{0}\left[\frac{h\left(c_{55} \kappa \alpha_{m}^{2}+c_{44} \kappa \beta_{n}^{2}+2 s^{2} \rho_{p}\right)}{2}+s c_{w} \rho_{w}\right]-c_{55} h \kappa \alpha_{m} \\
\quad \times \frac{\widetilde{\bar{\psi}}_{x z}}{2}-\frac{c_{44} h \kappa \beta_{n} \widetilde{\bar{\psi}}_{y z}}{2}=\frac{8 \eta_{1} t_{d} p_{m}}{\left[a b\left(s t_{d}+1\right)\right]} .
\end{gathered}
$$

Solving (27), (28), and (33) yields the analytical solutions in the Fourier and Laplace transformed domains for an airbacked plate:

$$
\begin{aligned}
& \widetilde{\bar{w}}_{0}=\frac{32 p_{m} t_{d} \eta_{1}\left(\eta_{3}^{2}-\eta_{2} \eta_{4}\right)}{\left[a b\left(1+s t_{d}\right) \eta_{8}\right]}, \\
& \widetilde{\bar{\psi}}_{x z}=\frac{16 h \kappa p_{m} t_{d} \eta_{1}\left(c_{44} \beta_{n} \eta_{3}-c_{55} \alpha_{m} \eta_{4}\right)}{\left[a b\left(1+s t_{d}\right) \eta_{8}\right]}, \\
& \widetilde{\bar{\psi}}_{y z}=\frac{16 h \kappa p_{m} t_{d} \eta_{1}\left(c_{55} \alpha_{m} \eta_{3}-c_{44} \beta_{n} \eta_{2}\right)}{\left[a b\left(1+s t_{d}\right) \eta_{8}\right]},
\end{aligned}
$$

where

$$
\begin{aligned}
\eta_{7}= & \frac{h\left(\kappa c_{55} \alpha_{m}^{2}+\kappa c_{44} \beta_{n}^{2}+2 s^{2} \rho_{p}\right)}{2}+s c_{w} \rho_{w}, \\
\eta_{8}= & h^{2} \kappa^{2}\left[c_{44} \beta_{n}\left(c_{44} \beta_{n} \eta_{2}-2 c_{55} \alpha_{m} \eta_{3}\right)+c_{55}^{2} \alpha_{m}^{2} \eta_{4}\right] \\
& +4\left(\eta_{3}^{2}-\eta_{2} \eta_{4}\right) \eta_{7} .
\end{aligned}
$$

4.3. Water-Backed. Similarly to the air-backed case, for the water-backed plate case, the fundamental (12)-(13) are rewritten in both Fourier and Laplace transformed domains and are the same as (27)-(28). Moreover, by substituting (1), (4), and (16)-(19) into (14), this equation can be rewritten as

$$
\begin{gathered}
\frac{2 c_{w} \rho_{w} \dot{\bar{w}}_{0}+h \rho_{p} \ddot{\bar{w}}_{0}-c_{55} h \kappa \alpha_{m} \bar{\psi}_{x z}}{2}-\frac{c_{44} h \kappa \beta_{n} \bar{\psi}_{y z}}{2} \\
+\frac{h \kappa \bar{w}_{0}\left(c_{55} \alpha_{m}^{2}+c_{44} \beta_{n}^{2}\right)}{2}=\frac{8 \eta_{1} p_{m} \exp \left(-t / t_{d}\right)}{a b} .
\end{gathered}
$$

Applying the Laplace transform to (36) yields:

$$
\begin{gathered}
\widetilde{\bar{w}}_{0}\left[\frac{h\left(c_{55} \kappa \alpha_{m}^{2}+c_{44} \kappa \beta_{n}^{2}+2 s^{2} \rho_{p}\right)}{2}+2 s c_{w} \rho_{w}\right]-c_{55} h \kappa \alpha_{m} \\
\quad \times \frac{\widetilde{\bar{\psi}}_{x z}}{2}-\frac{c_{44} h \kappa \beta_{n} \widetilde{\bar{\psi}}_{y z}}{2}=\frac{8 \eta_{1} t_{d} p_{m}}{\left[a b\left(s t_{d}+1\right)\right]} .
\end{gathered}
$$

Solving (27), (28), and (37) yields the analytical solutions in the transformed domains:

$$
\begin{gathered}
\widetilde{\bar{w}}_{0}=\frac{32 p_{m} t_{d} \eta_{1}\left(\eta_{3}^{2}-\eta_{2} \eta_{4}\right)}{\left[a b\left(1+s t_{d}\right) \eta_{10}\right]}, \\
\widetilde{\bar{\psi}}_{x z}=\frac{16 h \kappa p_{m} t_{d} \eta_{1}\left(c_{44} \beta_{n} \eta_{3}-c_{55} \alpha_{m} \eta_{4}\right)}{\left[a b\left(1+s t_{d}\right) \eta_{10}\right]}, \\
\widetilde{\bar{\psi}}_{y z}=\frac{16 h \kappa p_{m} t_{d} \eta_{1}\left(c_{55} \alpha_{m} \eta_{3}-c_{44} \beta_{n} \eta_{2}\right)}{\left[a b\left(1+s t_{d}\right) \eta_{10}\right]},
\end{gathered}
$$

where

$$
\begin{aligned}
\eta_{9}= & \frac{h\left(\kappa c_{55} \alpha_{m}^{2}+\kappa c_{44} \beta_{n}^{2}+2 s^{2} \rho_{p}\right)}{2}+2 s c_{w} \rho_{w}, \\
\eta_{10}= & h^{2} \kappa^{2}\left[c_{44} \beta_{n}\left(c_{44} \beta_{n} \eta_{2}-2 c_{55} \alpha_{m} \eta_{3}\right)+c_{55}^{2} \alpha_{m}^{2} \eta_{4}\right] \\
& +4\left(\eta_{3}^{2}-\eta_{2} \eta_{4}\right) \eta_{9} .
\end{aligned}
$$

At this point, the analytical solutions for the three cases in the transformed domains have been obtained, and subsequently, the final solutions for the displacement distributions are obtained by the inversion of Fourier and Laplace transforms. The Fourier inversion can be carried out by utilizing (16), and the Laplace inversion can be carried out by adopting an analytical inversion method, which is expressed as follows [23-25].

The solutions for the displacements in (30), (34), and (38) can be rewritten in a general and simpler form as

$$
\tilde{f}(s)=\frac{A(s)}{B(s)},
$$

where $\widetilde{f}(s)$ denotes a displacement solution in the Laplace transformed domain, both functions $A(s)$ and $B(s)$ are in form of polynomials, and the degree of $A(s)$ is less than that of $B(s)$.

If all the roots of $B(s)$ are simple, then the original function is [23-25]

$$
f(t)=\sum_{k=1}^{n} \frac{A\left(s_{k}\right)}{B^{\prime}\left(s_{k}\right)} \exp \left(s_{k} t\right)
$$

When $B(s)$ has complex roots, the original function becomes [23-25]

$$
f(t)=\sum_{i=1}^{n_{r}} \frac{A\left(s_{i}\right)}{B^{\prime}\left(s_{i}\right)} \exp \left(s_{i} t\right)+2 \operatorname{Re} \sum_{j=1}^{n_{c}} \frac{A\left(s_{j}\right)}{B^{\prime}\left(s_{j}\right)} \exp \left(s_{j} t\right),
$$

where $s_{k}, s_{i}$, and $s_{j}$ are the roots, the real roots, and the complex roots with positive imaginary parts of $B(s)$, respectively, $n, n_{r}$, and $n_{c}$ are the numbers of $s_{k}, s_{i}$, and $s_{j}$, respectively, the superscript $\left({ }^{\prime}\right)$ stands for the derivative with respect to $s$, and Re stands for the real part of the complex number. 
TABLE 1: The parameters of the underwater explosion, geometry for the analytical and FEA methods, and the Fourier transform parameters.

\begin{tabular}{cccccccccccccc}
\hline$W(\mathrm{~kg})$ & $S(\mathrm{~m})$ & $p_{m}(\mathrm{MPa})$ & $t_{d}(\mathrm{~ms})$ & $a(\mathrm{~m})$ & $b(\mathrm{~m})$ & $h(\mathrm{~m})$ & $\rho_{w}\left(\mathrm{~kg} / \mathrm{m}^{3}\right)$ & $c_{w}(\mathrm{~m} / \mathrm{s})$ & $x_{\text {len }}(\mathrm{m})$ & $y_{\text {len }}(\mathrm{m})$ & $z_{\text {len }}(\mathrm{m})$ & $m_{\max }$ & $n_{\max }$ \\
\hline 1 & 5 & 8.46 & 0.137 & 1 & 1 & 0.15 & 1000 & 1500 & 0.025 & 0.025 & 0.025 & 11 & 11 \\
\hline
\end{tabular}

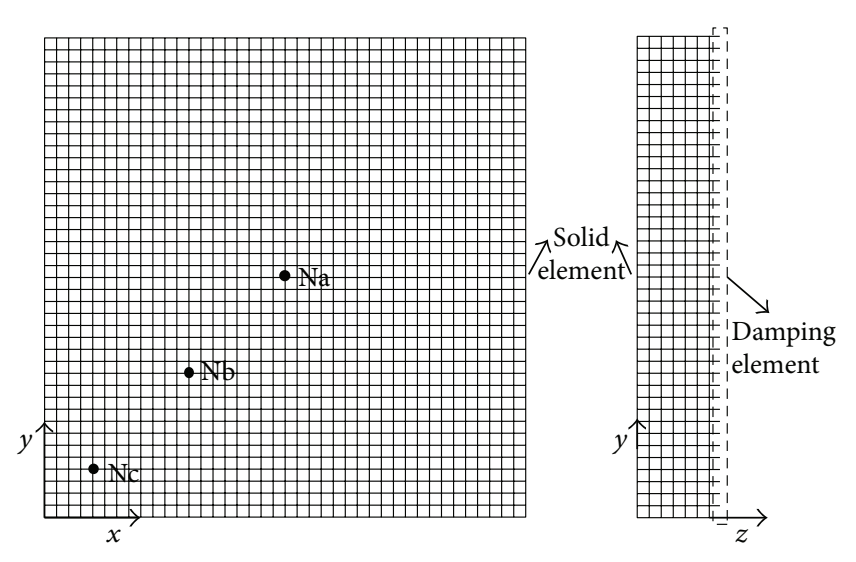

Figure 2: The model used for the FEA.

\section{Results and Discussions}

A Mathematica package was developed for the analytical method described herein. First, for an air-backed plate, the results of the analytical method are validated by a comparison with a finite element analysis (FEA) performed using the commercial software ANSYS. Subsequently, the influences of the FSI and the thickness are investigated.

5.1. Validation of the Analytical Method by Comparing with FE Method. For an air-backed plate, the analytical method is validated by comparing the results of this method with those obtained by the FEA. A simply supported plate is shown in Figure 1, and the corresponding FEA model is shown in Figure 2. The plate is simulated by solid45 elements, and Combin14 damping elements are used to the damping term in (1). The elastic properties, explosive characteristics, and geometric parameters are listed in Tables 1 and 2, where $x_{\text {len }}$ and $y_{\text {len }}$ are the element lengths in the $x$ and the $y$ directions, respectively, of the FEA model for the laminated plate. The variable $z_{\text {len }}$ is the element length in the $z$ direction, and $m_{\max }$ and $n_{\max }$ are the maximum values of $m$ and $n$, respectively.

In Figure 3, the response-time histories of $w, \sigma_{x x}, \sigma_{y y}, \sigma_{x y}$, $\sigma_{x z}, \sigma_{y z}$, and $\sigma_{m}$ of the back face $(z=h / 2)$ and middle face $(h=0)$ at $\mathrm{Na}(x=y=0.5 \mathrm{~m}), \mathrm{Nb}(x=y=0.3 \mathrm{~m})$, and Nc $(x=y=0.1 \mathrm{~m})$ are calculated by the analytical and the FEA methods for the air-backed case and are compared. In Figure 4, the distributions of the deflection $w$ and the von Mises stress $\sigma_{m}$ on the back face of the plate when $t=0.45 \mathrm{~ms}$ are calculated by the analytical and the FEA methods for the air-backed case and are compared. The time-histories and the distributions of the responses between the two solution methods correspond closely.

5.2. Validation of the Analytical Method by Comparing with Experiment Results. In this section, the analytical method is
TABLE 2: The elastic constants of the plate material.

\begin{tabular}{lcccccc}
\hline$\rho_{p}\left(\mathrm{~kg} / \mathrm{m}^{3}\right)$ & $\begin{array}{c}c_{11} \\
(\mathrm{GPa})\end{array}$ & $\begin{array}{c}c_{12} \\
(\mathrm{GPa})\end{array}$ & $\begin{array}{c}c_{22} \\
(\mathrm{GPa})\end{array}$ & $\begin{array}{c}c_{44} \\
(\mathrm{GPa})\end{array}$ & $\begin{array}{c}c_{55} \\
(\mathrm{GPa})\end{array}$ & $\begin{array}{c}c_{66} \\
(\mathrm{GPa})\end{array}$ \\
\hline 7850 & 215.54 & 18.48 & 61.58 & 55.26 & 161.54 & 161.54 \\
\hline
\end{tabular}

TABLE 3: Geometry and elastic parameters of the aluminum plate.

\begin{tabular}{lccccc}
\hline $\begin{array}{l}\text { Length } \\
a(\mathrm{~m})\end{array}$ & $\begin{array}{c}\text { Width } \\
b(\mathrm{~m})\end{array}$ & $\begin{array}{c}\text { Thickness } \\
h(\mathrm{~m})\end{array}$ & $\begin{array}{c}\text { Young's } \\
\text { modulus } \\
E(\mathrm{GPa})\end{array}$ & $\begin{array}{c}\text { Poisson's } \\
\text { ratio } \\
\mu\end{array}$ & $\begin{array}{c}\text { Density } \\
\rho\left(\mathrm{kg} / \mathrm{m}^{3}\right)\end{array}$ \\
\hline 1 & 1 & 0.01 & 70 & 0.3 & 2700 \\
\hline
\end{tabular}

validated by comparing the acceleration of the air-backed aluminum plate calculated by this method with those obtained by the Hung et al.s underwater explosion experiment result [26]. Hung performed the experiment within a $4 \times 4 \times 4 \mathrm{~m}$ water tank. The isotropic aluminum target plate was fixed to an empty steel casing, known as a "shock rig", and the button of which was fixed to a steel base. In this paper, it is assumed that the plate is simply supported. The geometry and elastic properties of the plate is shown in Table $3.1 \mathrm{~g}$ charge $(W=1 \mathrm{~g}$ ) was located on the normal line through the center of the plate. An accelerometer was placed in the center of the plate and operated at a sampling rate of $2.0 \mathrm{MHz}$. Four tests, with different standoff distances, were carried out, although only the case with a standoff distance of $0.7 \mathrm{~m}(S=0.7 \mathrm{~m})$ was used for the comparisons made here. The water density is $\rho_{w}=1000 \mathrm{~kg} / \mathrm{m}^{3}$, and the shock wave (acoustic) velocity in the water is $c_{w}=1500 \mathrm{~m} / \mathrm{s}$.

Figure 5 compares the acceleration time histories at the center of the plate between analytical method and experiment [26]. Obviously, the time histories by the two methods agree with each other closely in the overall trend. There are some differences between the two time history curves. The acceleration peak value of analytical method is 25.6 percent greater than that of experiment. The growth can be attributed to the fact that the pressure precursor is ignored in the incident wave profile. It is understandable since the pressure precursor significantly decreases the peak of incident pressure according to [27]. In addition, there are some high-frequency vibrations in the experiment record, which are missing in the curve by the analytical method. The difference may be caused by the FSI model formulated by Taylor used here which ignores the bubble impulsive pressure. In general, the analytical method proposed in this paper and its FSI model have been validated.

5.3. The Influence of the Fluid-Solid Interaction and the Thickness. In this section, the effects of the FSI and the thickness are investigated by the analytical method. Five different thicknesses $(h=0.05 \mathrm{~m}, 0.10 \mathrm{~m}, 0.15 \mathrm{~m}, 0.20 \mathrm{~m}$, 


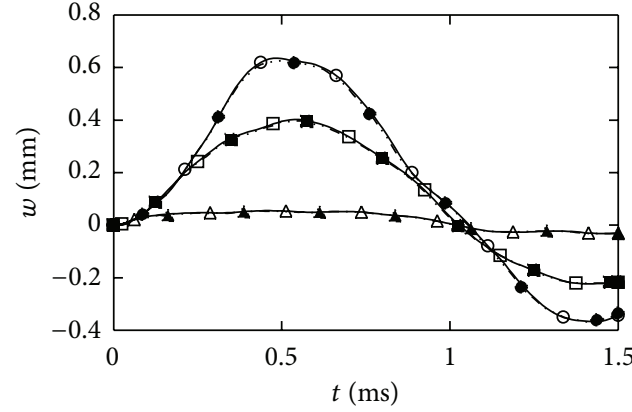

(a)

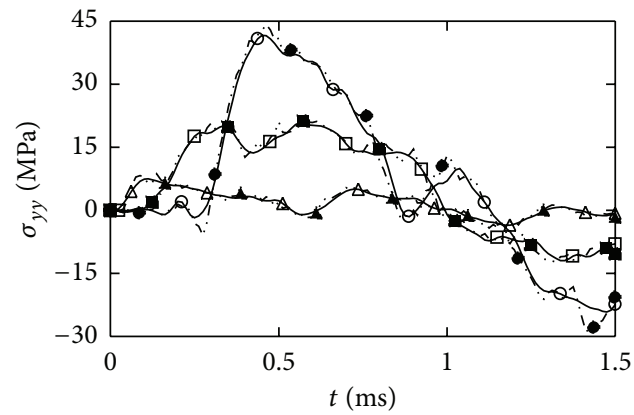

(c)

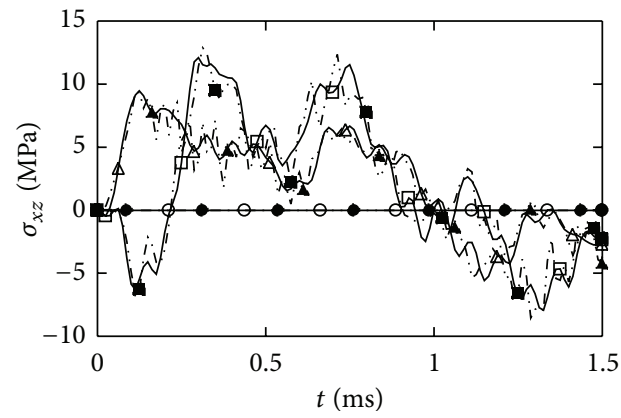

(e)

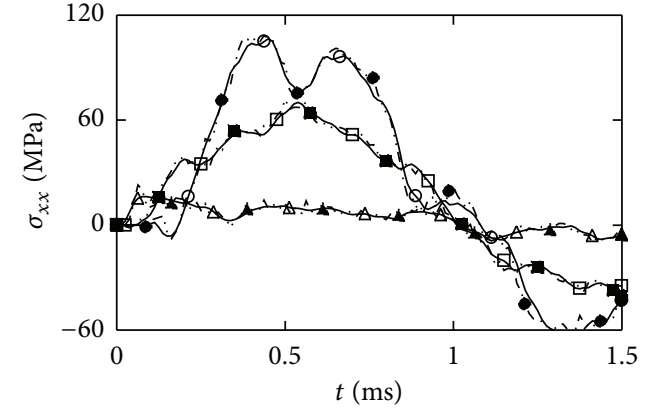

(b)

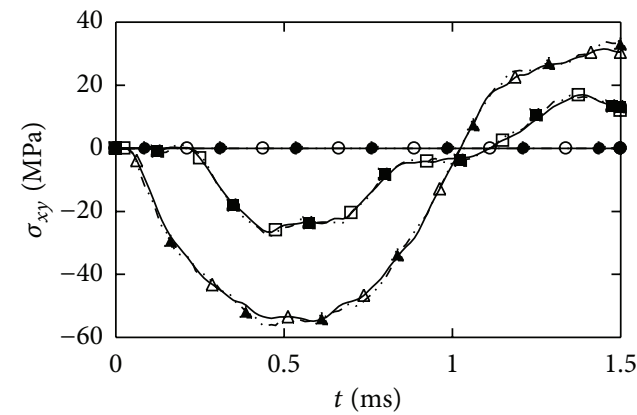

(d)

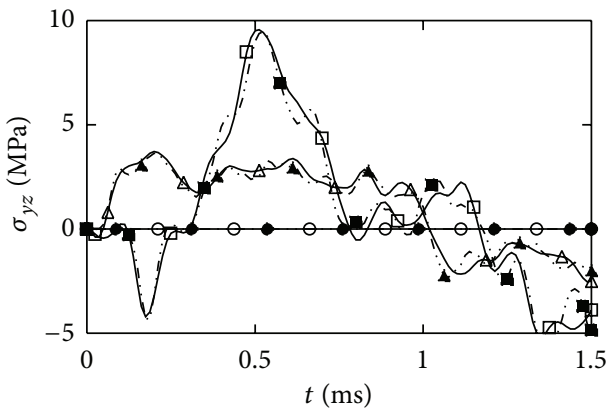

(f)

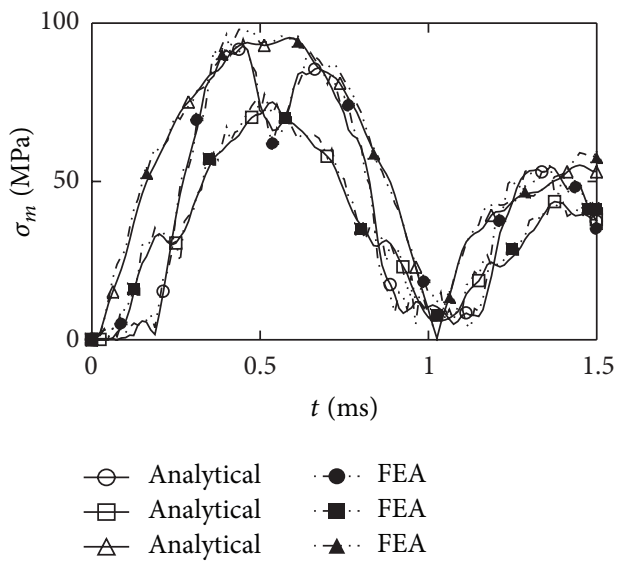

(g)

FIGURE 3: Comparisons of the response-time histories calculated by both the analytical and the FEA methods for the air-backed cases: (a) the time histories of the deflection $w$ of the back face at $\mathrm{Na}, \mathrm{Nb}$, and $\mathrm{Nc}$; (b) the time histories of the membrane normal stress $\sigma_{x x}$ of the back face at $\mathrm{Na}, \mathrm{Nb}$, and $\mathrm{Nc}$; (c) the time histories of the membrane normal stress $\sigma_{y y}$ of the back face at $\mathrm{Na}, \mathrm{Nb}$, and Nc; (d) the time histories of the membrane shear stress $\sigma_{x y}$ of the back face at $\mathrm{Na}, \mathrm{Nb}$, and Nc; (e) the time histories of the transverse shear stress $\sigma_{x z}$ of the middle face at $\mathrm{Na}, \mathrm{Nb}$, and $\mathrm{Nc}$; (f) the time histories of transverse shear stress $\sigma_{y z}$ of the middle face at $\mathrm{Na}, \mathrm{Nb}$, and $\mathrm{Nc}$; and (g) the time histories of the von Mises stress $\sigma_{m}$ of the back face at $\mathrm{Na}, \mathrm{Nb}$, and $\mathrm{Nc}$. 


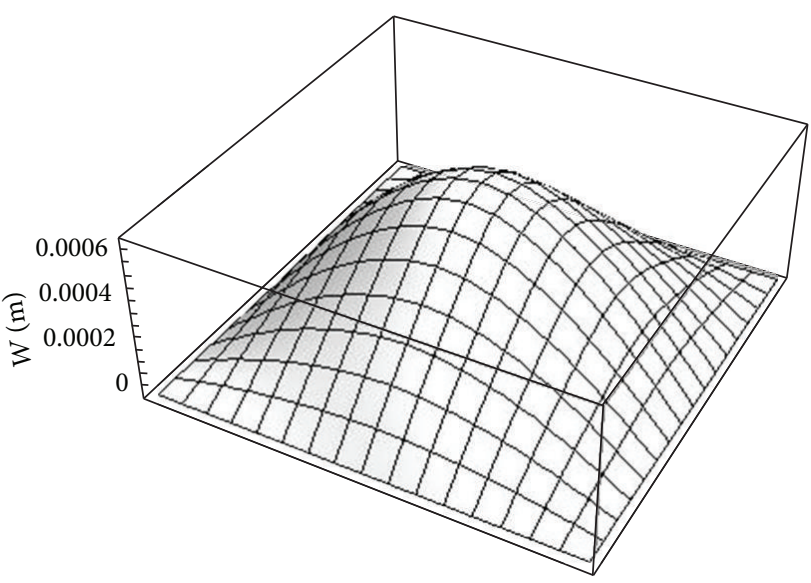

(a)

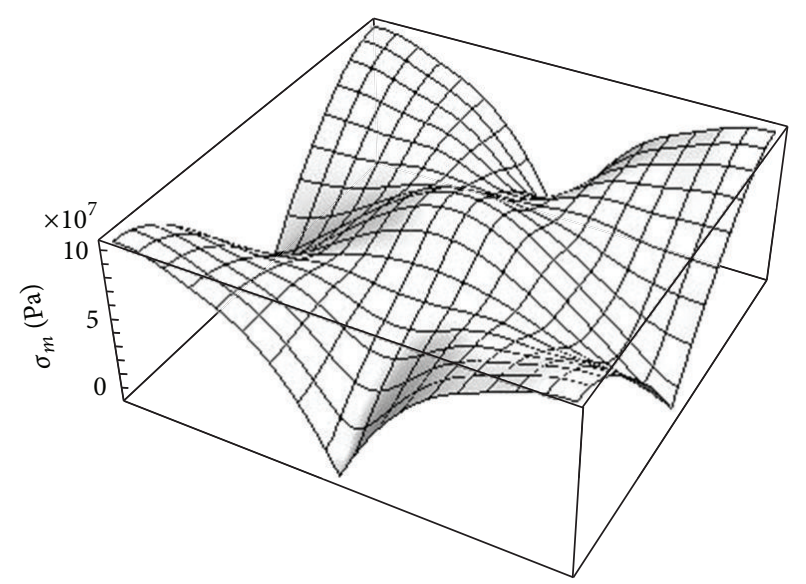

(c)

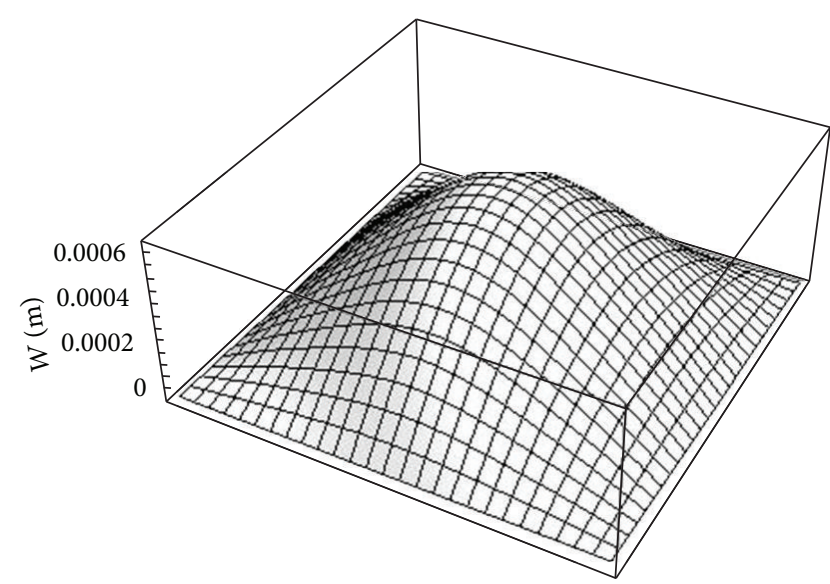

(b)

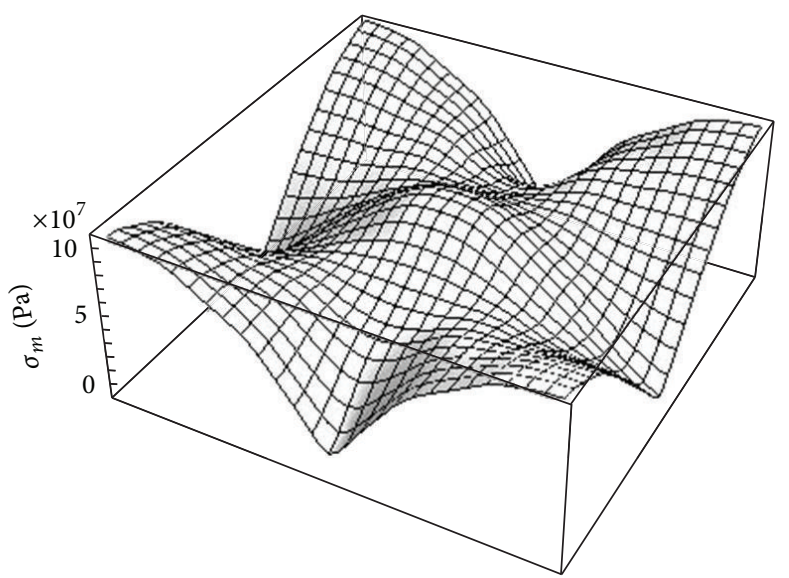

(d)

FIGURE 4: Comparisons of the responses of the plate calculated by both the analytical and the FEA methods for the air-backed case when $t=0.45$ ms: (a) the deflection $w$ of the back face of the plate calculated by the analytical method; (b) the deflection $w$ of the back face of the plate calculated by the FEA method; (c) the von Mises stress $\sigma_{m}$ of the back face of the plate calculated by the analytical method; and (d) the von Mises stress $\sigma_{m}$ of the back face of the plate calculated by the FEA method.

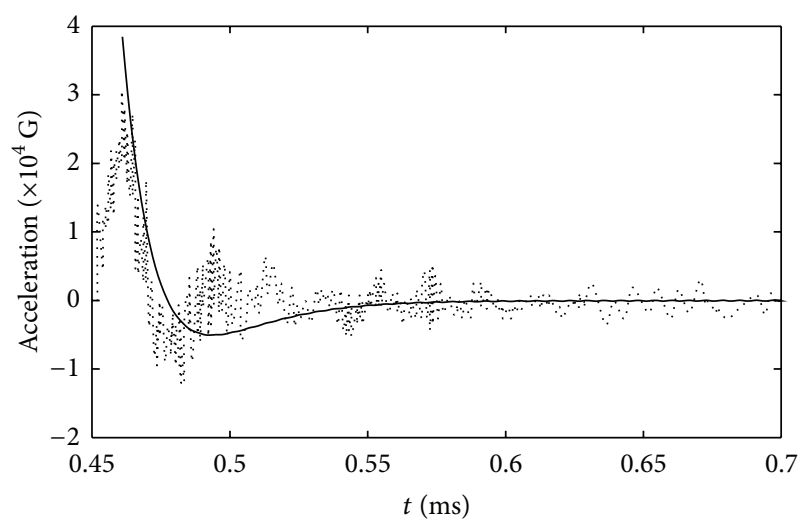

Experiment

- Analytical

FIgURE 5: Comparisons of the acceleration time histories at the center of the plate between analytical method and experiment [26].
$0.25 \mathrm{~m}$, and $0.30 \mathrm{~m}$ ) and three cases, including the nonFSI, air-backed, and water-backed cases, are considered. The elastic properties, explosive characteristics, and geometric parameters, except for the thickness, are listed in Tables 1 and 2. In Figure 6, the extreme values of the responsetime histories of $w, \sigma_{x x}$, and $\sigma_{x z}$ of the different thicknesses and the FSI cases are compared. The thickness and FSI effects significantly influence the reaction of the laminated plate.

As shown in Figures 6(a), 6(d), and 6(g), all of the extreme values of the response-time histories for the non-FSI case decrease as the thickness increases. As shown in Figures 6(b), 6(c), and 6(e), the deflection, $w$, and the membrane normal stress $\sigma_{x x}$ in the air-backed and water-backed cases also decrease as the thickness increases. However, as shown in Figures 6(f), 6(h), and 6(i), the peak values of the responsetime histories for the case of $h=0.05 \mathrm{~m}$ are less than those of $h=0.10 \mathrm{~m}$. 


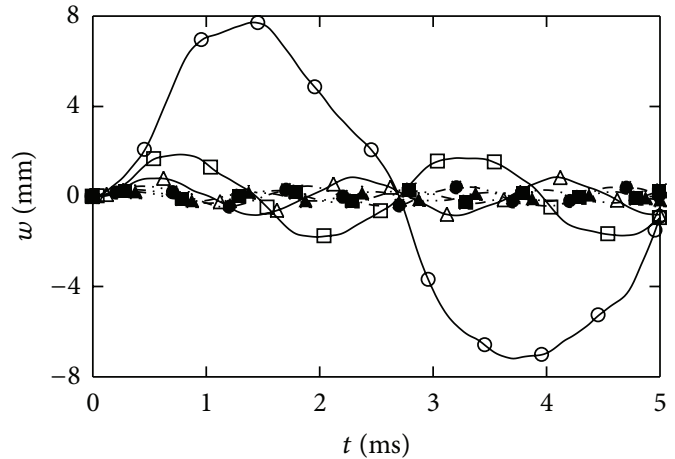

(a)

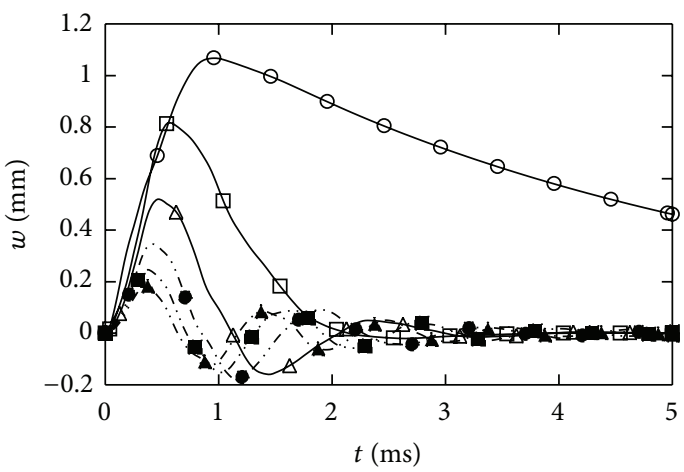

(c)

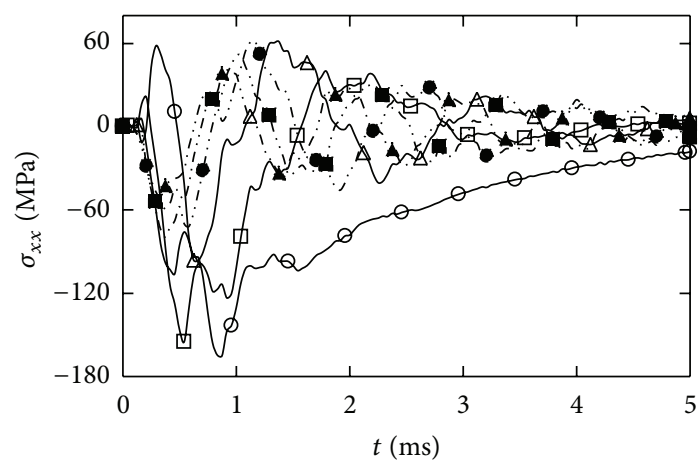

(e)

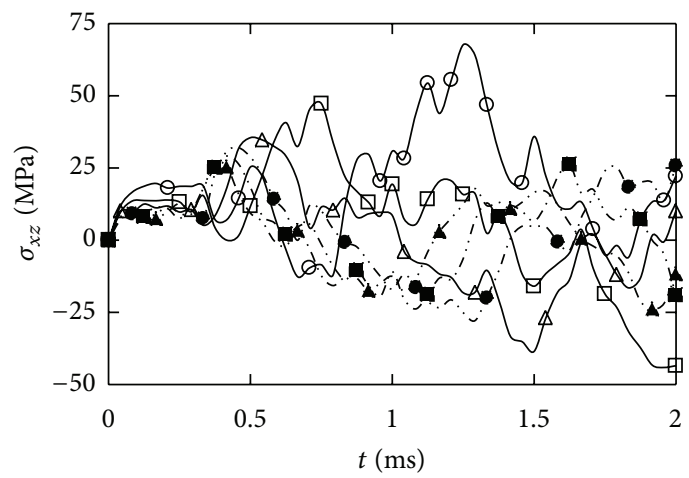

$$
\begin{aligned}
& \begin{array}{lll}
Ð h=0.05 & \bullet \cdot \cdot h=0.2 \\
\square h=0.1 & \bullet \cdot h=0.25
\end{array} \\
& \triangle h=0.15 \quad \triangle \quad \cdot h=0.3
\end{aligned}
$$

(g)

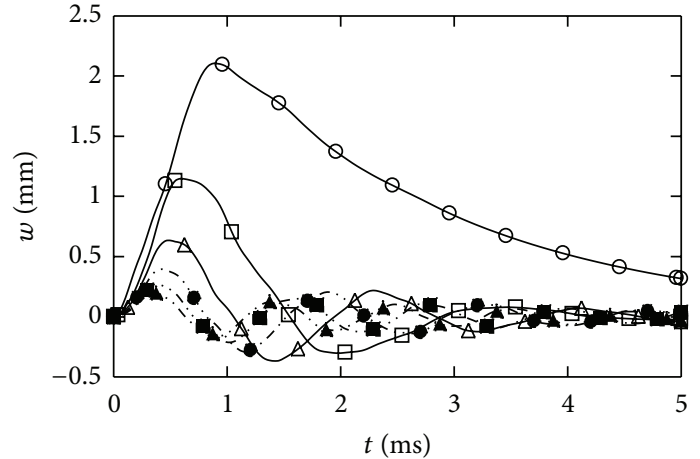

(b)

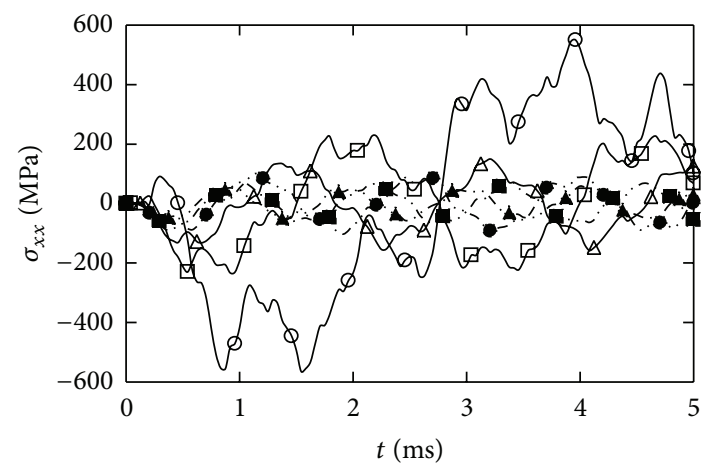

(d)

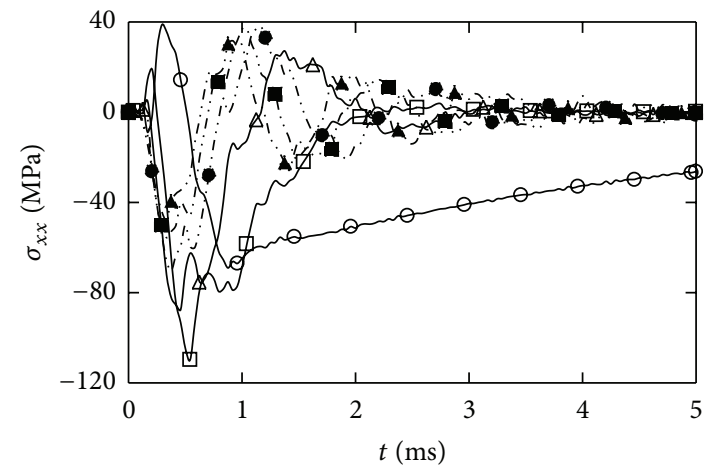

(f)

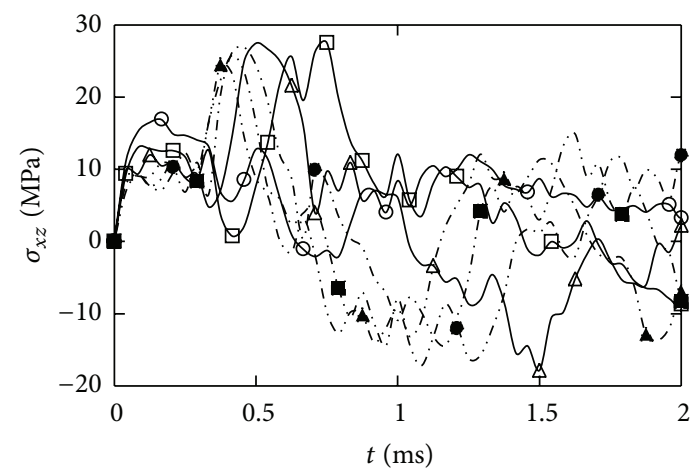

$$
\begin{aligned}
& \bigcirc h=0.05 \quad \bullet \quad h=0.2 \\
& \square h=0.1 \quad \cdot \quad h=0.25 \\
& \triangle h=0.15 \quad \text { \ } h=0.3
\end{aligned}
$$

(h)

FIgure 6: Continued. 


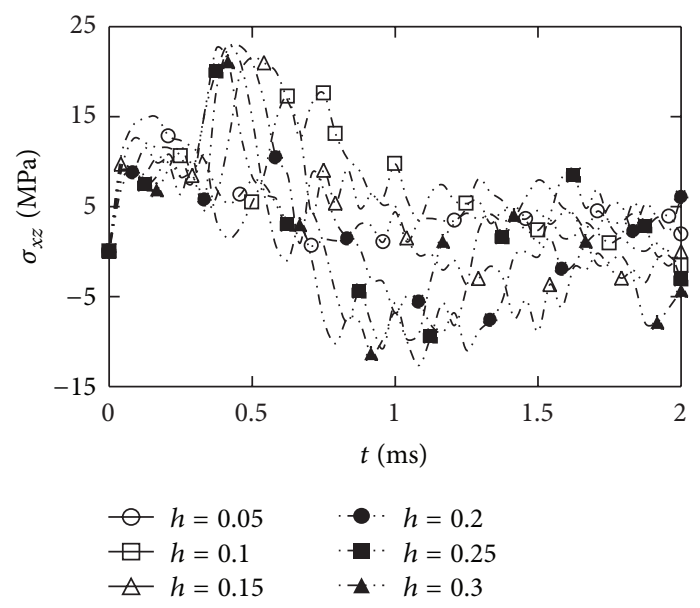

(i)

FIGURE 6: Comparisons of the responses of the plate for five different thicknesses: (a) the time history of the deflection $w$ for the plate at $x=a / 2, y=b / 2$, and $z=h / 2$ for the non-FSI case; (b) the time history of the deflection $w$ for the plate at $x=a / 2, y=b / 2$, and $z=h / 2$ for the air-backed case; (c) the time history of the deflection $w$ for the plate at $x=a / 2, y=b / 2$, and $z=h / 2$ for the water-backed case; (d) the time history of the membrane normal stress $\sigma_{x x}$ for the plate at $x=a / 2, y=b / 2$, and $z=h / 2$ for the non-FSI case; (e) the time history of the membrane normal stress $\sigma_{x x}$ for the plate at $x=a / 2, y=b / 2$, and $z=h / 2$ for the air-backed case; (f) the time history of the membrane normal stress $\sigma_{x x}$ for the plate at $x=a / 2, y=b / 2$, and $z=h / 2$ for the water-backed case; (g) the time history of the transverse shear stress $\sigma_{x z}$ for the plate at $x=0, y=0.5$, and $z=0$ for the non-FSI case; (h) the time history of the transverse shear stress $\sigma_{x z}$ for the plate at $x=0, y=0.5$, and $z=0$ for the air-backed case; and (i) the time history of the transverse shear stress $\sigma_{x z}$ for the plate at $x=0, y=0.5$, and $z=0$ for the water-backed case.

\section{Conclusions}

It is in the interest of designers to know the transient state of stress in advance that develops in a plate during an underwater explosion. However, to the best of the authors' knowledge, the analytical method in the relevant literature for the dynamic response of plates to underwater explosion does not consider the FSI differences between the different positions on front and back faces of plate. The purpose of this paper is to fill this gap. Involving the planar wave assumption, an analytical method was proposed based on the FSI model formulated by Taylor [15], the Mindlin plate theory, Laplace transform, and its inversion to model the elastic dynamic response of a plate subjected to an underwater explosion. This new analytical method builds upon the Reissner-Mindlin plate theory and includes the shear deformation and the FSI (fluid-solid interaction) effect. Additionally, the new method is three-dimensional, considers the moment and the membrane stress in the plate, and examines the full profile of possibilities, such as the non-FSI, the air-backed, and waterbacked cases.

The response-time histories and the response distributions on the plate in terms of displacements and stresses between the analytical method and the FEA method were compared to validate the analytical method, and good agreement was found. Subsequently, the simplified method for fluid-solid interaction as well as the analytical method are validated by comparison of the acceleration at the center of an air-backed plate between analytical method and the experiment performed by Hung et al. [26].

The thickness and FSI effects significantly influence the reaction of the laminated plate. All of the extreme values of the response-time histories for the non-FSI case decrease as the thickness increases. However, considering the FSI effects for the air-backed and water-backed cases, some peak values of the response-time histories for the $h=0.05 \mathrm{~m}$ case are less than those of $h=0.10 \mathrm{~m}$.

The inclusion of FSI effects in designs for plates is vital for a full understanding of the dynamic response, and the results can be used as benchmark solutions in further research. In addition, several types of fluid-solid interaction effects during UNDEX near the plate are coupled in the present method, including Taylor's FSI effects, bending-stretching effects, and simply boundary effects [12]; the respective effect of each type is not presented here and will be discussed elsewhere.

\section{Acknowledgments}

The authors gratefully acknowledge the financial support provided by the National Natural Science Foundation of China (nos. 51209185, 51079127, 51179171, and 51279180), China Postdoctoral Science Foundation (no. 2013M531462), and the Postdoctoral Science Foundation of Zhejiang Province (no. Bsh1202057). Special thanks should go to the Ansys and Mathematica software used in this work.

\section{References}

[1] R. Rajendran and J. M. Lee, "Blast loaded plates," Marine Structures, vol. 22, no. 2, pp. 99-127, 2009.

[2] R. Rajendran and K. Narasimhan, "Linear elastic shock response of plane plates subjected to underwater explosion," 
International Journal of Impact Engineering, vol. 25, no. 5, pp. 493-506, 2001.

[3] R. Rajendran, J. K. Paik, and B. J. Kim, "Design of warship plates against underwater explosions," Ships and Offshore Structures, vol. 1, no. 4, p. 347, 2006.

[4] G. M. Genin and V. Birman, "Micromechanics and structural response of functionally graded, particulate-matrix, fiberreinforced composites," International Journal of Solids and Structures, vol. 46, no. 10, pp. 2136-2150, 2009.

[5] T. Hause, "Advanced functionally graded plate-type structures impacted by blast loading," International Journal of Impact Engineering, vol. 38, no. 5, pp. 314-321, 2011.

[6] L. Librescu, S. Y. Oh, and J. Hohe, "Dynamic response of anisotropic sandwich flat panels to underwater and in-air explosions," International Journal of Solids and Structures, vol. 43, no. 13, pp. 3794-3816, 2006.

[7] L. Librescu, S. Y. Oh, and J. Hohe, "Linear and non-linear dynamic response of sandwich panels to blast loading," Composites Part B, vol. 35, no. 6-8, pp. 673-683, 2004.

[8] L. Librescu, T. Hause, and C. J. Camarda, "Geometrically nonlinear theory of initially imperfect sandwich curved panels incorporating nonclassical effects," AIAA Journal, vol. 35, no. 8, pp. 1393-1403, 1997.

[9] L. Librescu, S. Y. Oh, and J. Hohe, "Implication of nonclassical effects on dynamic response of sandwich structures exposed to underwater and in-air explosions," Journal of Ship Research, vol. 51, no. 2, pp. 83-93, 2007.

[10] J. Leblanc and A. Shukla, "Dynamic response of curved composite panels to underwater explosive loading: experimental and computational comparisons," Composite Structures, vol. 93, no. 11, pp. 3072-3081, 2011.

[11] G. J. McShane, V. S. Deshpande, and N. A. Fleck, "Underwater blast response of free-standing sandwich plates with metallic lattice cores," International Journal of Impact Engineering, vol. 37, no. 11, pp. 1138-1149, 2010.

[12] Y. L. Young, Z. Liu, and W. Xie, "Fluid-structure and shockbubble interaction effects during underwater explosions near composite structures," Journal of Applied Mechanics, vol. 76, no. 5, pp. 1-10, 2009.

[13] Z. Xue and J. W. Hutchinson, "A comparative study of impulseresistant metal sandwich plates," International Journal of Impact Engineering, vol. 30, no. 10, pp. 1283-1305, 2004.

[14] A. Idesman, H. Samajder, E. Aulisa, and P. Seshaiyer, "Benchmark problems for wave propagation in elastic materials," Computational Mechanics, vol. 43, no. 6, pp. 797-814, 2009.

[15] G. I. Taylor, "The pressure and impulse of submarine explosion waves on plates," in The Scientific Papers of Sir Geoffrey Ingram Taylor, vol. 3, pp. 287-303, Cambridge, UK, 1963.

[16] Z. Liu and Y. L. Young, "Transient response of submerged plates subject to underwater shock loading: an analytical perspective," Journal of Applied Mechanics, vol. 75, no. 4, Article ID 044504, 5 pages, 2008.

[17] R. M. McMeeking, A. V. Spuskanyuk, M. Y. He, V. S. Deshpande, N. A. Fleck, and A. G. Evans, "An analytic model for the response to water blast of unsupported metallic sandwich panels," International Journal of Solids and Structures, vol. 45, no. 2, pp. 478-496, 2008.

[18] Y. Liang, A. V. Spuskanyuk, S. E. Flores et al., "The response of metallic sandwich panels to water blast," Journal of Applied Mechanics, vol. 74, no. 1, pp. 81-99, 2007.
[19] M. T. Tilbrook, V. S. Deshpande, and N. A. Fleck, “The impulsive response of sandwich beams: analytical and numerical investigation of regimes of behaviour," Journal of the Mechanics and Physics of Solids, vol. 54, no. 11, pp. 2242-2280, 2006.

[20] V. S. Deshpande and N. A. Fleck, "One-dimensional response of sandwich plates to underwater shock loading," Journal of the Mechanics and Physics of Solids, vol. 53, no. 11, pp. 2347-2383, 2005.

[21] R. H. Cole, Underwater Explosions, Princeton University Press, Princeton, NJ, USA, 1948.

[22] C. F. Hung, P. Y. Hsu, and J. J. Hwang-Fuu, "Elastic shock response of an air-backedplate to underwater explosion," International Journal of Impact Engineering, vol. 31, no. 2, pp. 151-168, 2005.

[23] A. H. Akbarzadeh, S. K. Hosseinizad, M. R. Eslami, and M. Sadighi, "Mechanical behaviour of functionally graded plates under static and dynamic loading," Proceedings of the Institution of Mechanical Engineers, Part C: Journal of Mechanical Engineering Science, vol. 225, no. 2, pp. 326-333, 2011.

[24] Y. Kiani, M. Shakeri, and M. R. Eslami, "Thermoelastic free vibration and dynamic behaviour of an fgm doubly curved panel via the analytical hybrid Laplace-fourier transformation," Acta Mechanica, vol. 223, no. 6, pp. 1199-1218, 2012.

[25] A. H. Akbarzadeh, M. Abbasi, and M. R. Eslami, "Coupled thermoelasticity of functionally graded plates based on the third-order shear deformation theory," Thin-Walled Structures, vol. 53, pp. 141-155, 2012.

[26] C. F. Hung, P. Y. Hsu, and J. J. Hwang-Fuu, "Elastic shock response of an air-backed plate to underwater explosion," International Journal of Impact Engineering, vol. 31, no. 2, pp. 151-168, 2005.

[27] Z. Liu and Y. L. Young, "Shock-structure interaction considering pressure precursor," in Proceedings of the 28th Symposium on Naval Hydrodynamics, pp. 12-17, Pasadena, Calif, USA, 2010. 


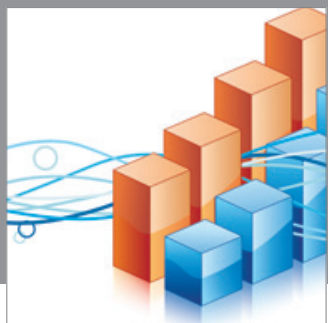

Advances in

Operations Research

mansans

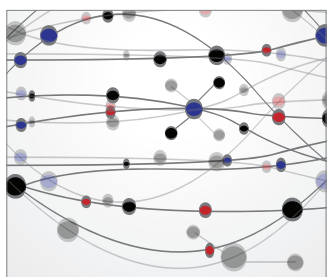

The Scientific World Journal
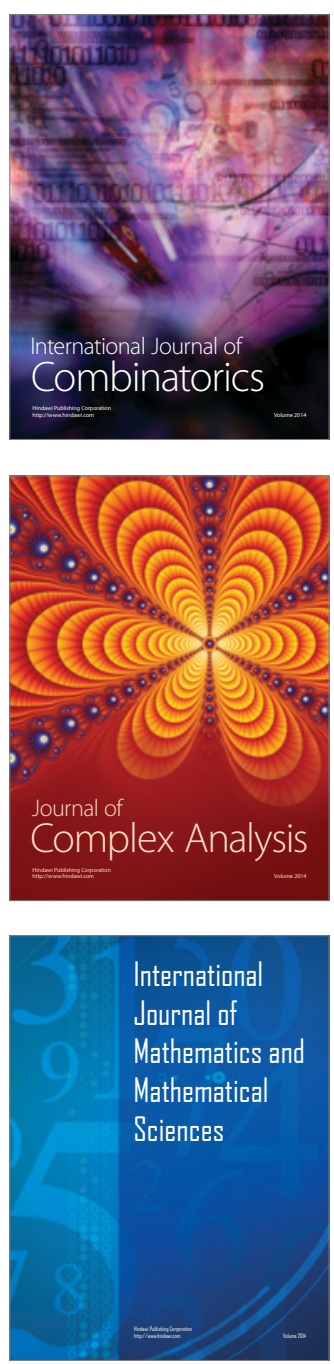
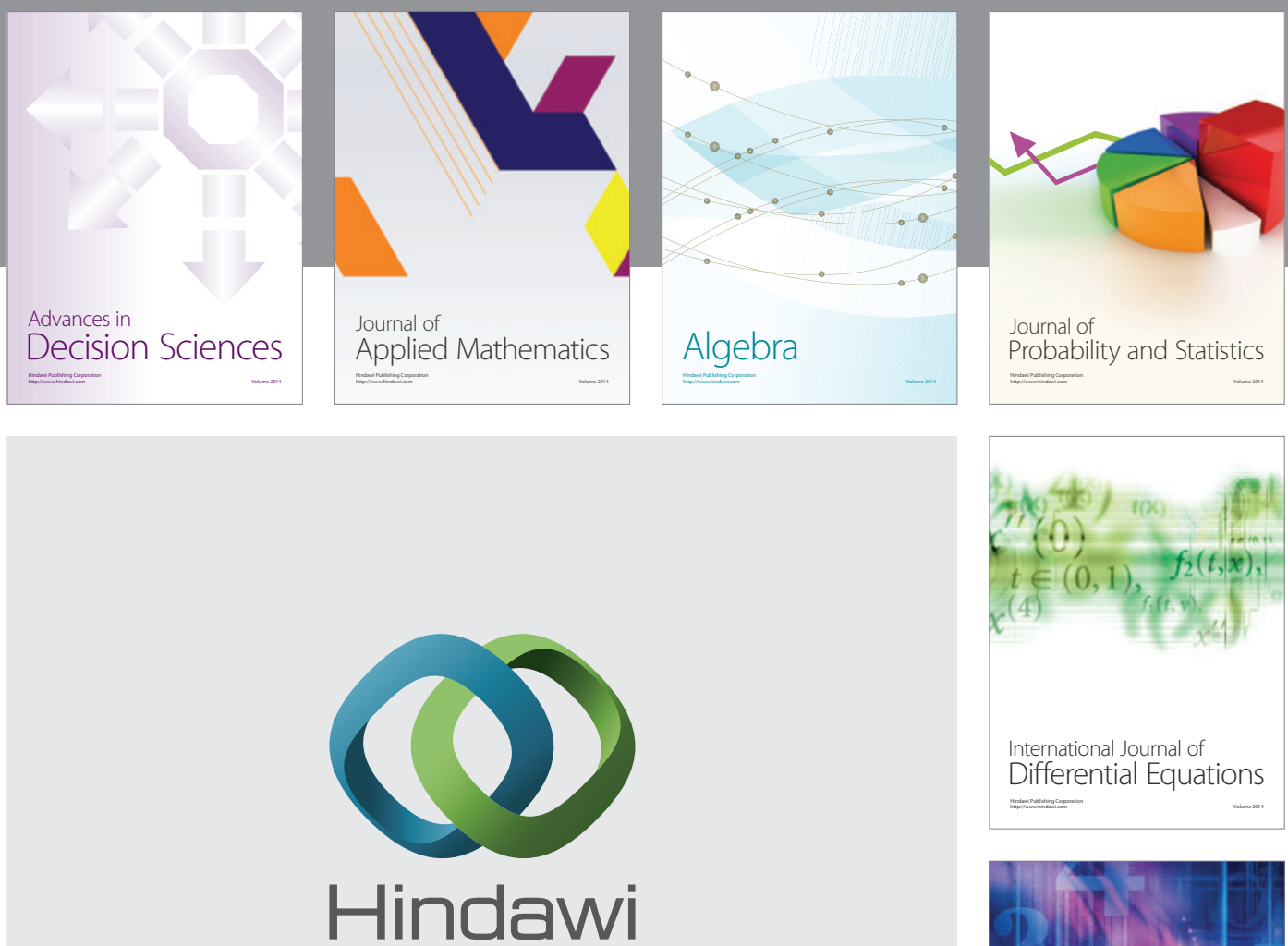

Submit your manuscripts at http://www.hindawi.com
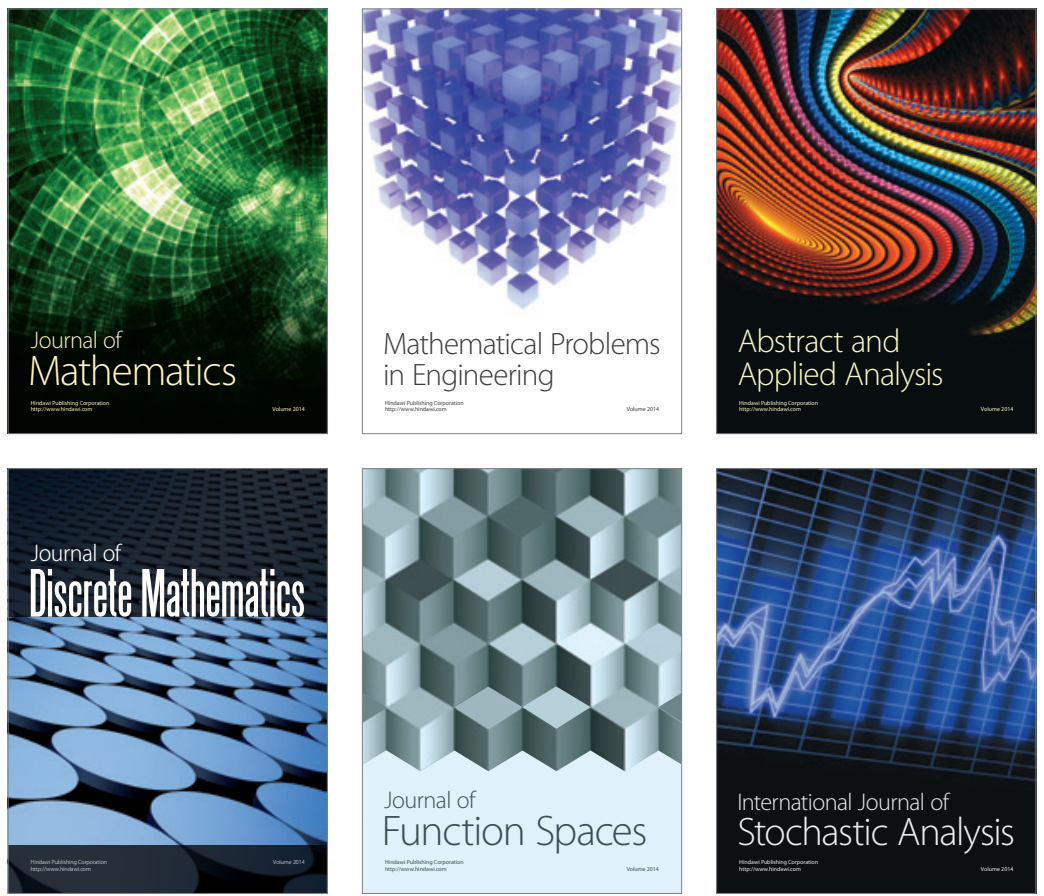

Journal of

Function Spaces

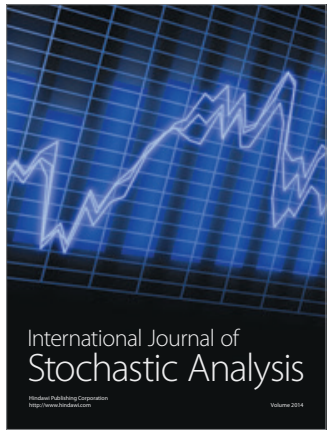

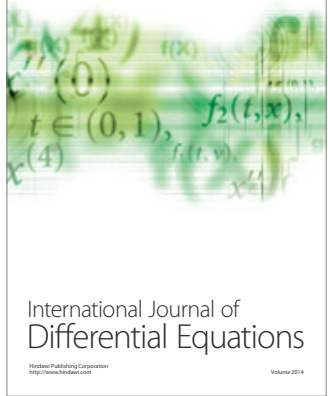
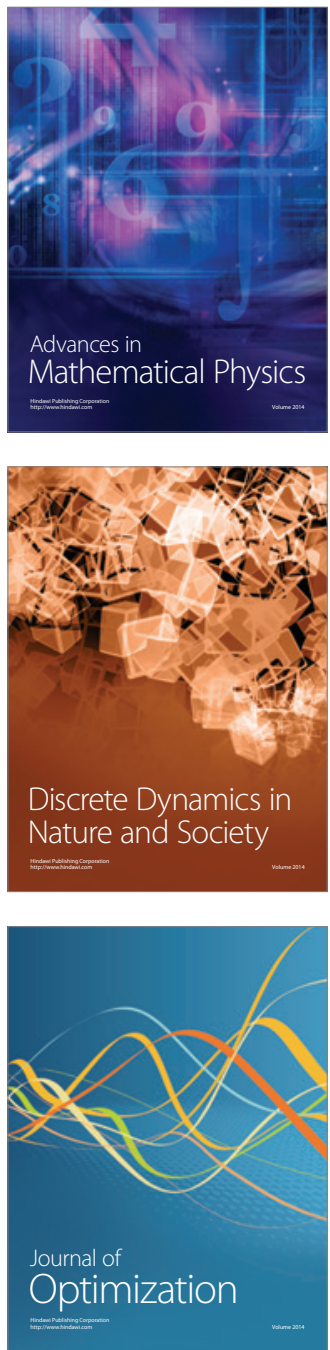